\title{
Osteoarthritis in horses - Part 1: relationship between clinical and radiographic examination for the diagnosis
}

\author{
Maria Verônica de Souza ${ }^{1 *}$ \\ ${ }^{1}$ Universidade Federal de Viçosa, Departamento de Medicina Veterinaria, Viçosa, Minas Gerais, Brasil.
}

\begin{abstract}
Locomotor disorders are very common in the equine clinic, which may be partly due to the different types of activities horses develop. Osteoarthritis (OA), commonly known as degenerative joint disease, presents an considerable role in the series of disorders of the musculoskeletal system and may be associated with other problems such as navicular syndrome, periostitis or osteochondrosis. This affection causes progressive deterioration of articular cartilage, accompanied by bone and soft-tissue periarticular changes. In fact, it results from a complex interaction between biochemical and biomechanical factors. The objective of this article is to review information about clinical and radiographic findings of $O A$, the biochemical and biomechanical changes manifested in the disease and the importance of the synovial fluid. Additionally, some information on other species is also presented. This review refers to Part 1 of a study whose sequence is entitled "Osteoarthritis in horses - Part 2: a review of the intra-articular use of corticosteroids as a method of treatment."
\end{abstract}

Keywords: equine, degenerative joint disease, synovitis, cartilage degeneration, pathology of articular disease.

\footnotetext{
${ }^{1}$ Authors for correspondence: msouzavet@ gmail.com
} 


\section{INTRODUCTION}

Osteoarthritis (OA) is a very common disease in several species. MclIwraith et al. (2012) provided information mentioned by other authors regarding the frequency of the disease in the United States and the European Union. According to Lawrence et al. (2008), in 2008, it was estimated that approximately 27 million adults in the United States had clinical OA (up from the estimate of 21 million for 1995). Altman et al. (2006) estimated that 100 million people had OA in the European Union.

An epidemiological study published by Rosis et al. (2010), which sampled patients in long-stay institutions, revealed that $36.9 \%$ of elderly residents included within the study had OA. The disease was more frequent $(70.9 \%)$ in females, and femorotibial and patellofemoral joints were particularly affected. A study carried out by Oliveira and Braga (2010) obtained data from patients referred to a physical therapy clinic related to orthopedics and traumatology at Universidade Paulista (UNIP)/Brazil, in which women accounted for over $60 \%$ of cases. A larger number of females $(62.37 \%)$ with locomotor problems was revealed, and OA was the most common condition (19.92\%).

In horses, OA compromises the equine industry, not only due to the costs of treatment, but also as a consequence of delayed return to athletic performance. Although there are many epidemiological studies addressing the prevalence of the disorder, there are reports of its high incidence (more than 80\%) even in Mangalarga Marchador foals aged between 12 and 36 months (Garcia et al. 2009), which proves that this condition affects adult and elderly horses, but can also develop in young horses and foals (McIIwraith 1982; Riggs et al. 1999; Kawcak et al. 2001, Garcia et al. 2009). It is due, in many cases, to the premature start of horse training during the early stages of musculoskeletal system development or due to excessive and/or prolonged mechanical loads on immature articular cartilage, with periarticular tissues inadequately developed to support intense loads (Garcia et al. 2009). The disease is a very common complaint in the institution of the author of the present study. Over the past three years, approximately $30 \%$ of treated horses had osteoarthritis in some joints, some associated with other diseases such as navicular syndrome, periostitis or osteochondrosis.

Neundorf et al. (2010) studied the prevalence, as well as the severity of metacarpophalangeal joint osteoarthritis racehorses using quantitative macroscopic evaluations of joints from fifty animals at different ages. The data showed that one-third of horses with 2- and 3-year-old presented partial or thickness lesions in the cartilage, as well as OA. In addition, the severity of the disease increased until horses reached six years of age. According to the authors, it is necessary to study the factors that might make 2year-old horses susceptible to early joint affection, including genetic, nutritional and management factors. Therefore, the objective of this article is to review information about clinical and radiographic findings of osteoarthritis, as well as some biochemical and biomechanical aspects related to the disease.

\section{DEVELOPMENT}

Osteoarthritis, also known as degenerative joint disease and, occasionally, as osteoarthrosis, is considered an important locomotor disorder that affects many species, and is particularly common in humans and horses (Peloso et al. 1994; McIIwraith 2005b; van Weeren and de Grauw 2010; Ferris et al. 2011; Chiaradia et al. 2012).

\section{Clinical and radiographic findings}

Osteoarthritis is characterized clinically by varying levels of lameness and, consequently, pain, and it is an expensive equine health problem due to the loss of limb functionality with restricted movement of the injured joint (Jeffcott et al. 1982; May 1996; Pool 1996; Lees 2003; Ferris et al. 2011; Andia et al. 2012; McIIwraith et al. 2012), as observed in humans (Andia et al. 2012; McIIwraith et al. 2012). In addition, the presence of synovial effusion (particularly in the early stage of the disease), softtissue swelling and response to flexion are also common clinical signs (McIIwraith et al. 2012). In fact, this disease is among the main causes of both anticipation horse retirement of pleasure-riding and performance equine (Rossdale et al. 1985; Pearson and Lindinger 2009) and economic losses. Osteoarthritis is also seen frequently in the joints of thoracolumbar and lumbar regions in the horse column, which causes back pain and changes in the gait of the animal (Alves et al. 2007).

It can be divided into subclinical, active (similar to a noninfectious inflammatory process) and clinically overt or decompensated stages (McIIwraith et al. 2012). Usually, 
the joint undergoes a progressive loss of cartilage and changes in the bone and regional soft tissues (McIIwraith and Vachon 1988; Yang et al. 2001; McIIwraith 2005b; van Weeren and de Grauw 2010; Ferris et al. 2011). The degenerative process leads to cracking, ulceration, and/or loss of full-thickness articular surfaces (Brandt et al. 2008). Radiographic findings in horses are well known. Initially, destruction of articular cartilage and decreased joint space occur, which are occasionally difficult to visualize on radiographs (McIIwraith et al. 2012). Overloads of the articular surfaces cause subchondral bone sclerosis (with occasional lysis or cyst-like lesions in subchondral bone) accompanied by bone osteophytes at the edges of the articular surfaces, which can be very large (Yang et al. 2001). Enthesophytes at attachments within the fibrous joint capsule or ligaments and even dystrophic mineralization capsules may also be observed (McIIwraith and Vachon 1988; Pool 1996; Kawcak et al. 2008; McIIwraith et al. 2012). The proximity of the subchondral bones results in ankylosis (particularly in joints with little movement) during advanced stages of the disease (Kerbyson et al. 2013). The osteophyte, which is an attempt at bone repair (Andia et al. 2012; McIIwraith et al. 2012) or joint immobilization (Pool 1996), is considered the main radiographic finding of osteoarthritis (Andia et al. 2012; McIlwraith et al. 2012). However, a research performed in joints such as the distal interphalangeal, proximal interphalangeal, metacarpophalangeal, metatarsophalangeal, as well as carpal, tarsal and femorotibial-patellar of 152 horses at approximately eight years of age, of different breeds and physical activities, highlighted the lack of a relationship between scores of radiographic findings and lameness presented by animals (Veiga 2006). The same was mentioned by Baccarin et al. (2012b).

\section{Biomechanical and Biochemical Aspects}

The optimal balance between the anabolic and catabolic activities of chondrocytes is essential to maintaining the integrity of the cartilage and to repair the molecular changes that occur daily. The understanding that there is an imbalance between these activities makes it necessary that therapies that promote anabolic effects and inhibit catabolic actions be adopted (Mueller and Tuan 2011).

The articular biology and pathogenetic mechanisms that are involved in $\mathrm{OA}$ are quite similar among mammalian species. Therefore, discoveries regarding pain control and the evolution of the condition in horses readily benefit from studies conducted in humans. It is well known in both species that osteoarthritis is directly related to biomechanical mechanisms (abnormal load on healthy cartilage or normal load on damaged cartilage) (McIIwraith 2005b). However, failure to repair the damaged cartilage results not only in abnormal biomechanical conditions, but also biochemical changes. Not only bone but also cartilages receive and spread the stress occurred during locomotion and loading, and are thus continuously challenged biomechanically (Lories and Luyten 2011). Brandt et al. (2009) consider the disease to be due to a failure of appropriate repair after an injury caused by excessive mechanical stress (defined as an area of strength per unit). In this context, several primary and secondary factors can cause the disease, and the mechanical impact of a single event or repetitive microtrauma could lead to the development of joint damage that requires the intrinsic process of repair, which may fail or be successful in restoring articular function (Cantley et al. 1999; Kim et al. 2003; van Weeren and de Grauw 2010). According to Lories and Luyten (2011), OA is related to a mechanically induced joint disorder caused by both acquired and genetic factors.

Regarding the biochemical changes, the disease is characterized by a reduced formation of proteoglycans and unusual increase of collagen type $\mathrm{X}$ expression by chondrocytes in the synovium. (Yang et al. 2001). Early intervention in cases of OA may be possible after trauma. Therefore, it is necessary to understand the biochemical mechanisms (Chiaradia et al. 2012) that occur in the joint. Chondrocyte hypertrophy, the increased production of extracellular matrix molecules and the remodeling of bones, may occur (Andia et al. 2012). Under physiological conditions, a sparse amount of chondrocytes ( 1 to $2 \%$ of the volume of the cartilage) is distributed throughout the matrix, which consists primarily of type II collagen (approximately 15\% of hyaline cartilage), proteoglycans, and water (approximately $75 \%$ of hyaline cartilage) (van Weeren and de Grauw 2010; McIIwraith et al. 2012). The structure and arrangement of the matrix macromolecules to influence the physical properties of this tissue (Jurvelin et al. 1988). Although the cartilage presents a connective tissue with very specialized functions, with biomechanical characteristics such as load-bearing and shock absorption, the 
biomechanical properties depend on the completeness of the collagen network, as well as the synthesis and retention of proteoglycans (Eyre and Wu 1995; van Weeren and Brahma 2001).

Once the degenerative process is started, it will stimulate the production of transforming growth factor- $\beta$ (TGF- $\beta$ ), which is a multivalent cytokine composed of three homologous isoforms (1,2 and 3 ) that stimulates the synthesis of collagen type II and proteoglycans (Grimaud et al. 2002; Walshe et al. 2009). Transforming growth factor- $\beta$ signaling promotes the differentiation of mesenchymal stem cells into chondrocytes and allows the repair of defects in the cartilage. Moreover, although growth factors are generally related to protective outcomes, it has been suggested that TGF- $\beta$ can have a dual role in osteoarthritis, i.e., both positive and negative effects.

According to Scharstuhl et al. (2002), the formation of osteophytes is favored by the presence of this growth factor and enhanced by the hepatocyte growth factor in non-inflammatory conditions. However, to promote cell differentiation, TGF- $\beta$ is used in culture medium to induce chondrogenic differentiation of stem cells (Yang et al. 2001; Radcliffe et al. 2010; Mueller and Schier 2011) and bone morphogenetic proteins (BMPs) (Kasashima et al. 2011; Stewart and Stewart 2011), which are members of the supergene family of TGF- $\beta$.

The signaling pathway of BMP is known to be important for the maintenance of articular cartilage in health conditions (Yang et al. 2001; Oshin and Stewart 2007). Many individual molecules of BMP have been characterized, and four are known to have osteogenic activity (Wang et al. 1990; Chen et al. 1991; Hammonds et al. 1991; Wozney 1992). The positive response to differentiation may be evaluated histologically by using special stains or may be determined from gene expression in signaling pathways, such as aggrecan and type II collagen (de Schauwer et al. 2011), which are fundamental components of the extracellular matrix. According to Lorie and Luyten (2011), the BMPs appear to influence the OA, and they can activate cellular and molecular processes.

Yang et al. (2001) carried out an in vitro study to investigate the intracellular protein Smad3, which transduces extracellular signals from TGF- $\beta 3$ signals to the nucleus, where they activate downstream gene transcription. According to the authors, the $\mathrm{TGFb} / \mathrm{Smad} 3$ signals inhibit the hypertrophic differentiation of mice chondrocyte and are important for maintenance of articular cartilage.

Osteoarthritis in horses can start by injury in the articular cartilage, synovial membrane (or synovium), subchondral bone, ligaments, or fibrous joint capsule, or it may be a combination of several problems that occur concurrently. Both synovitis and capsulitis, which are common diseases in equine athletes, are accompanied by pain and discomfort, which can lead to an imbalance between anabolic and catabolic activities of chondrocytes (Loeser 2006). These conditions release enzymes that contribute to the degradation of articular cartilage, such as matrix metalloproteinases (MMPs) and aggrecanases, inflammatory mediators (e.g., PGs: prostaglandins) and free radicals and cytokines, such as tumor necrosis factor-alpha (TNF- $\alpha)$ and interleukin 1 (IL-1). The interaction between cytokines results in the enzymatic degradation of proteoglycans and type II collagen (McIIwraith et al. 2012). According to van Weeren and de Grauw (2010), the intense vascularization of the subsynovial tissue and the ability of synovial cells to produce different types of mediators and catabolic enzymes make the synovium a fundamental component in all types of joint involvement.

Veiga (2006) reported that several of the biomechanical factors that act on the joint surfaces could result in synovitis as a consequence of the production and release of several cytokines, which can stimulate the activation of MMPs and other components of the inflammatory process. Consequently, an imbalance occurs between the synthesis and degradation of proteoglycans and the glycosaminoglycans (GAGs), which constitute the cartilaginous matrix. Both biomechanical and biochemical changes are involved in the onset of OA. In addition, it appears that subchondral bone sclerosis and synovial inflammation present a fundamental function in the pathophysiology of the disease.

Baccarin et al. (2012a) used the urinary GAGs excretion to investigate the efficiency of chondroitin sulfate (CS) and glucosamine $(\mathrm{GlcN})$ in the treatment of 27 horses presenting mild osteoarthritis. According to the authors, the therapy causes a long-lasting increase of CS, as well as of keratin sulfate in the urine. In addition, it improves the flexion of the metacarpophalangeal and tarsocrural joints. 
Origin of Pain

Pain is the most important sign of OA, and its management is crucial for the equine practitioner (van Weeren and de Grawn 2010). However, although pain with consequent lameness is the main clinical sign of OA, its association with joint damage is still poorly understood. The origin of the pain is not in the cartilage because its anatomical structure has no nociceptive fibers. According to Felson (2009), these fibers are found in the synovium, periosteum, subchondral bone and articular capsule and in the meniscus of the stifle joint and the marrow of long bones. Raffa (2003) reported that mechanical and chemical stimuli (resulting from inflammation of the tissue) are responsible for pain originating in synovial joints. The authors also mentioned that these stimuli were detected and delivered by different types of receptors. Synovitis, which was mentioned previously as a possible cause of OA, is an important component for the onset of pain and occurs due to the activation of mechanoreceptors in the joint capsule and the chemical stimulation of nociceptors as a consequence of effusion, distention and/or fibrosis. This problem may cause both the activation of mechanoreceptors in the joint capsule and the direct chemical stimulation of nociceptors (van Weeren and de Grauw 2010).

Interleukins (IL-1 and IL-6) and TNFproinflammatory cytokines, are directly associated with pain (Svensson 2010), which may result from synovial macrophages. These cytokines incite chondrocytes to generate inflammatory mediators such as prostaglandin E2, superoxide, nitric oxide, proteolytic enzymes [disintegrin, metalloproteinase domains with thrombospondin motifs (ADAMTS) and MMPs] (Rutgers et al. 2009; Bondeson et al. 2010). However, studies have found no significant difference in the amount of PG E2 present in the synovial fluid (SF) of untreated horses or horses treated for lameness with intra-articular anesthetics. Moreover, substance $\mathrm{P}$ seems to be closely associated with OA joint pain (Fortier and Nixon 1997; de Grauw et al. 2006).

Coupled with mechanical stress are the degradation products of extracellular matrix that trigger signaling pathways that induce the transcription of nuclear factor-kappaB (NF-kB), which promotes an inflammatory response in the activated synovial fibroblasts. Furthermore, neurotrophins, especially the nerve growth factor, may induce more injuries through an inflammatory process by regulating the excitability of pain fibers or by making changes to the receptors and neuropeptides that are involved in the transmission of pain stimuli (Dray and Read 2007; Kress 2010).

The steroid receptor with nuclear actions regulates cell function by decreasing or increasing the expression of groups of genes in target tissues. In general, the hormone binds to the cytoplasmic receptor, and the complex then translocates to the nucleus by binding to specific DNA sequences. According to Glezer et al. (2000), the total quantity of these receptors expressed in a tissue can be modified by various hormonal treatments and drugs.

The relief of pain may result in an adequate clinical response in the short to midterm. However, over the long term, it can worsen the disease if training and physical activity management are not modified (van Weeren and de Grauw 2010). Therefore, it is essential to know the pathogenetic mechanisms of pain so that the therapy can be more focused. According to Dray and Read (2007), these mechanisms may include key receptors, ion channels and neurotrophin.

\section{Importance of Synovial Fluid}

The synovial fluid, which is a dialysate of blood plasma, has an important function in maintaining the viability of joints. It contains hyaluronic acid (HA), as well as lubricin glycoprotein and systemic signaling factors and locally produced cytokines (Knox et al. 1988; Schmidt et al. 2007). The synovial fluid is an essential component in joint homeostasis, because it works as a lubricant, allows movement between articular surfaces almost without friction, and transports nutrients and waste products to and from the avascular articular cartilage. In addition, SF can be used to monitor intra-articular events that are associated with changes in articular homeostasis, such as an influx of cells or inflammatory mediators and locally produced cytokines, and it can be used to monitor the by-products of tissue renewal (McIIwraith 2005a; van Weeren and Firth 2008). Finally, it is a source of chondroprogenitor cells (Stewart and Stewart 2011), which may be a tool to determine biomarkers (such as the $\mathrm{PG} \mathrm{E}_{2}$ ) that are related to OA in horses (Frisbie et al. 2008).

The possibility of using SF as a tool to investigate initial changes is very positive for the early diagnosis of the disease. According to Chiaradia et al. (2012), the volume of SF may be correlated with OA. Thus, there is the possibility of using SF to evaluate pathophysiological changes in various 
stages of subclinical disease. Kraus et al. (2007) quantified the concentration of urea in human, as described by Kraus et al. (2002), to determine the intra-articular volume of SF in joints lavaged with saline solution. According to these authors, there was a similarity between the serum levels of urea in SF and in the water fraction. This similarity should exist independently of joint injury, inflammation or age. Urea is not synthesized/metabolized by the articular tissues but spreads freely between the blood and intra-articular area (Maroudas 1970).

The determination of the gene expression of catabolic enzymes and cytokines in the SF, synovium, and articular cartilage of spontaneous OA in equine carpal joints was studied by Kamm et al. (2013). Their research revealed an essencial increase in the expression of disintegrin and metalloproteins with thrombospondin motifs 5 (ADAMTS-5) and of MMP-13 in the synovial tissue, as well as increases in both ADAMTS-4 and MMP-13 in the cartilage.

Jacobsen et al. (2006) determined the serum amyloid A (SAA) concentration in the serum and SF of 10 healthy horses and 21 horses with different types of joint disease. The effect of recurrent arthrocentesis on SAA concentrations in SF was evaluated using immunoturbidimetry. According to the authors, evaluating the SAA concentration in the synovial fluid was a good indicator for the diagnosis of joint infections, and it did not change in response to frequent arthrocenteses. However, it was not a valid marker in low-inflammation joint conditions. Therefore, it would not be indicated for OA.

\section{FINAL CONSIDERATIONS}

The articular cartilage and subchondral bone changes that manifest in OA are due to complex mechanisms that result from the interaction among biochemical, metabolic and biomechanical factors. As a consequence, it compromises the musculoskeletal system of the animal by causing pain and changes in the gait of the horse. Thus, besides affecting animal welfare, it compromises the physical and work performance of horses and represents economic losses to owners. The pain and presence of osteophytes can be regarded as the main clinical and radiographic findings, respectively. One of the main problems related to the low efficacy of the various treatments available for $\mathrm{OA}$ in horses is that the pathophysiology of the disease is still not completely well defined. Complex biochemical and biomechanical mechanisms are reported as involved in the degenerative process. Many of them have not only positive, but also negative effects. The presence of synovitis is considered an important pathophysiological aspect to the onset of pain. Accordingly, evaluation of changes in synovial fluid has been an attempt to detect the onset of OA. As mentioned previously, the concentration of urea can be used to determine the volume of SF in effused joints, since its quantification is not altered by the presence of a local inflammatory process. Therefore, future studies should consider the amount of this amide in SF to determine the real influence of the synovial membrane in the pathophysiological mechanism of OA and perhaps allow for early diagnosis. In fact, understanding the predisposing aspects and possible articular changes is essential in the choice of the proper treatment.

\section{ACKNOWLEDGMENTS}

The author is grateful to CAPES, FAPEMIG and $\mathrm{CNPq}$ for the usual financial support in her research projects.

\section{REFERENCES}

Altman RD, Abramson S, Bruyere O, Clegg D, HerreroBeaumont G, Maheu E, et al. Commentary: osteoarthritis of the knee and glucosamine. Osteoarth Cart. 2006;14(10):963-966.

Alves ALG, Fonseca BPA, Thomassian A, Nicoletti JLM, Hussni CA, Silveira CA. Lombalgia em equinos. Braz. J. vet. Res. anim. Sci. 2007; 44( 3):191-199

Andia I, Sánchez M, Maffulli N. Joint pathology and platelet-rich plasma therapies. Review. Expert Opin Biol Ther. 2012;12(1):7-22.

Baccarin RY, Machado, TS, Lopes-Moraes AP, Vieira FA, Michelacci YM. Urinary glycosaminoglycans in horse osteoarthritis. Effects of chondroitin sulfate and glucosamine. Res Vet Sci. 2012a;93(1):88-96.

Baccarin RYA, Moraes APL, Veiga ACR, Fernandes WR, Amaku M, Silva LCLC, Hagen SCF. Relação entre exame clínico e radiográfico no diagnóstico da osteoartrite equina. Braz $\mathrm{J} \mathrm{Vet}$ Anim Sci. 2012b;49(1):73-81.

Bondeson J, Blom AB, Wainwright S, Hughes C, Caterson B, van den Berg WB. The role of synovial macrophages and macrophage produced mediators in driving inflammatory and destructive responses in osteoarthritis. Arthritis Rheum. 2010;62(3):647-657. 
Brandt KD, Dieppe P, Radin EL. Etiopathogenesis of osteoarthritis. Rheum Dis Clin North Am. 2008;34(3):531-559.

Brandt KD, Dieppe P, Radin E. Etiopathogenesis of osteoarthritis. Med Clin N Am. 2009; 3:1-24.

Cantley CEL, Firth EC, Delahunt JW, Pfeiffer DU, Thompson KG. Naturally occuring osteoarthritis in the metacarpophalangeal joints of wild horses. Equine vet J. 1999;31(1):73-81.

Chen TL, Bates RL, Dudley A, Hammonds RG, Amento EP. Bone morphogenetic protein-2b stimulation of growth and osteogenic phenotypes in rat osteoblast-like cells: comparison with TGF- $\beta 1$. $J$ Bone Miner Res. 1991;6(12):1387-1393.

Chiaradia E, Pepe M, Tartaglia M, Scoppetta F, D'Ambrosio C, Renzone G, et al. Gambling on putative biomarkers of osteoarthritis and osteochondrosis by equine synovial fluid proteomics. J Proteomics. 2012;75(14):4478-4493.

de Grauw JC, van de Lest CHA, van Weeren PR, Brommer H, Brama PAJ. Arthrogenic lameness of the fetlock: synovial fluid markers of inflammation and cartilage turnover in relation to clinical joint pain. Equine vet J. 2006;38(4):305-311.

de Schauwer C, Meyer E, van de Walle GR, van Soom AV. Markers of stemness in equine mesenchymal stem cells: a plea for uniformity. Theriogenology. 2011;75(8):1431-1443.

Dray A, Read SJ. Arthritis and pain. Future targets to control osteoarthritis pain. Arthritis Res Ther. 2007;9(3):212.

Eyre DR, $\mathrm{Wu}$ JJ. Collagen structure and cartilage matrix integrity. J Rheumatol Suppl. 1995;43:82-85.

Felson DT. Developments in the clinical understanding of osteoarthritis. Arthritis Res Ther. 2009;11(1):203.

Ferris DJ, Frisbie DD, McIIwraith CW, Kawcak CE 2011 Current joint therapy usage in equine practice: A survey of veterinarians 2009. Equine vet $J$. 2011;43(5):530-535.

Fortier LA, Nixon AJ. Distributional changes in substance $\mathrm{P}$ nociceptive fiber patterns in naturally osteroarthritic articulations. $J$ Rheumatol. 1997;24(3):524-530.

Frisbie DD Al-Sobayil F Billinghurst RC Kawcak CE McIIwraith $\mathrm{CW}$. Changes in synovial fluid and serum biomarkers with exercise and early osteoarthritis in horses. Osteoarth Cart. 2008;16(10):1196-1204.

Garcia RS, Melo UP, Ferreira C, Toscano FS, Cruz GM. Estudo clínico e radiográfico da osteoartrite társica juvenil em potros da raça mangalarga marchador. Ciên Ani Bras. 2009;10(1):254-260.

Glezer I, Marcourakis T, Avellar MCW, Gorenstein C, Scavone C. O fator de transcrição NF-kB nos mecanismos moleculares de ação de psicofármacos. Rev Bras Psiquiatr. 2000;22(1):26-30.

Grimaud E, Heymann D, Redini F. Recent advances in TGF- $\beta$ effects on chondrocyte metabolism Potential therapeutic roles of TGF- $\beta$ in cartilage disorders. Cytokine Growth Factor Rev. 2002;13(3):241-257.

Hammonds RG, Schwall R, Dudley A, Berkemeier L, Lai C, Lee J,et al. Bone inducing activity of mature BMP-2b produced from a hybrid BMP-2a/2b precursor. Mol Endocrinol. 1991;5(1):149-155.

Jacobsen S, Thomsen MH, Nanni S. Concentrations of serum amyloid $\mathrm{A}$ in serum and synovial fluid from healthy horses and horses with joint disease. Am J Vet Res. 2006;67(10):1738-1742.

Jeffcott LB, Rossdale PD, Freestone J, Frank CJ, Towers-Clark PF. An assessment of wastage in Thoroughbred racing from conception to 4 years of age. Equine vet J. 1982;14(3):185-198.

Jurvelin J, Säämänen AM, Arokoski J, Helminen HJ, Kiviranta L, Tammi M. Biomechanical properties of canine knee articular cartilage as related to matrix proteoglycans and collagen. Eng Med. 1988;17(4):147-162.

Kamm JL, Frisbie DD, McIIwraith CW, Orr KE. Gene biomarkers in peripheral white blood cells of horses with experimentally induced osteoarthritis. Am J Vet Res. 2013;74(1):115-121.

Kasashima Y, Ueno T, Tomita A, Goodship AE, Smith RK. Optimisation of bone marrow aspiration from the equine sternum for the safe recovery of mesenchymal stem cells. Equine vet J. 2011;43(3):288-294.

Kawcak CE, Frisbie DD, Werpy NM, Park RD, McIIwraith CW. Effects of exercise vs experimental osteoarthritis on imaging outcomes. Osteoarth Cart. 2008;16(12):1519-1525.

Kawcak CE, McIIwraith CW, Norrdin RW, Park RD, James SP. The role of subchondral bone in joint disease: a review. Equine vet J. 2001;33(2):120-126.

Kerbyson K., Davison K., Sparks H. Science-in-brief: clinical highlights from BEVA congress 2012. Equine vet J. 2013;45(2):137-140.

Kim DY, Taylor HW, Moore RM, Paulsen DB, Cho DY. Articular chondrocyte apoptosis in equine osteoarthritis. Vet J. 2003;166(1):52-57.

Knox P, Levick JR, McDonald JN. Synovial fluid. Its mass, macromolecular content, and pressure in major limbs of the rabbit. $Q J$ Exp Physiol. 1988;73(1):33-36.

Kraus VB, Huebner JL, Fink C, King JB, Brown S, Vail $\mathrm{TP}$, et al. Urea as a passive transport marker for arthritis biomarker studies. Arthritis Rheum. 2002;46(2):420-427.

Kraus VB, Stabler TV, Kong SY, Varju G, McDaniel G. Measurement of synovial volume using urea. Osteoarthritis Cart. 2007;15(10):1217-1220.

Kress M. Nociceptor sensitization by pro-inflammatory cytokines and chemokines. Open Pain J. 2010;3:97106.

Lawrence RC, Felson DT, Helminck GG, Arnold LM, Choi H, Deyo RA, et al. Estimates of the prevalence of arthritis and other rheumatic conditions in the 
United States. Part I. Arthritis Rheum.

2008;58(1):15-25.

Lees P. Pharmacology of drugs used to treat osteoarthritis in veterinary practice Inflammapharmacol. 2003;11(4-6):385-399.

Loeser RF. Molecular mechanisms of cartilage destruction: mechanics, inflammatory mediators, and aging collide. Arthritis Rheum. 2006;54(5):1357-1360.

Lories RJ, Luyten FP. The bone-cartilage unit in osteoarthritis. Nat Rev. 2011;7(1):43-49.

Maroudas A. Distribution and diffusion of solutes in articular cartilage. Biophys $J$. 1970;10(5):365-379.

May SA. Radiological aspects of degenerative joint disease. Equine vet J. 1996;8(S3):16-22.

McIIwraith CW. Current concepts in equine degenerative joint disease. $J$ Am Vet Med Assoc. 1982;180(3):239-250.

McIIwraith CW. Use of synovial fluid and serum biomarkers in equine bone and joint disease: a review. Equine vet J. 2005a;37(5):473-482.

McIIwraith CW. Frank Milne lecture: from arthroscopy to gene therapy - 30 years of looking in joints. Proceedings of the Am Assoc Equine Pract. 2005;51:65-113.

McIIwraith CW, Frisbie DD, Kawcak CE. The horse as a model of naturally occurring osteoarthritis. Bone Joint Res. 2012;1(11):297-309.

McIIwraith CW Vachon AM. Review of pathogenesis and treatment of degenerative joint disease. Equine vet J Suppl. 1988;6:3-11.

Mueller P, Schier AF. Extracellular movement of signaling molecules. Dev Cell. 2011; 21(1):145-158.

Mueller MB, Tuan RS. Anabolic/catabolic balance in pathogenesis of osteoarthritis: identifying molecular targets. PM R Suppl. 1.2011;3:S3-S11.

Murray RC, DeBowes RM, Gaughan EM, Zhu CF, Athanasiou KA. The effects of intra-articular methylprednisolone and exercise on the mechanical properties of articular cartilage in the horse.

Osteoarthritis and Cartilage. 1988;6(2):106-114.

Neundorf RH, Lowerison MB, Cruz AM, Thomason JJ, McEwen BJ, Hurtig MB. Determination of the prevalence and severity of metacarpophalangeal joint osteoarthritis in Thoroughbred racehorses via quantitative macroscopic evaluation. Am J Vet Res. 2010;71(11):1284-1293.

Oliveira AC, Braga DL. Perfil epidemiológico dos pacientes atendidos na clínica de ortopedia da Universidade Paulista. $J$ Health Sci Inst. 2010;28(4):356-358.

Oshin AO, Stewart MC. The role of bone morphogenetic proteins in articular cartilage development, homeostasis and repair. Vet Comp Orthop Trauma. 2007;20(3):151-158.
Peloso JG, Mundy GD, Cohen ND. Prevalence of, and factors associated with, musculoskeletal racing injuries of Thoroughbreds. J Am Vet Med Assoc. 1994;204(4):620-626.

Pearson W, Lindinger M. Low quality evidence for glucosamine-based nutraceuticals in equine joint disease: review of in vivo studies. Equine vet $J$. 2009;41(7):706-712.

Pool RR. Pathologic manifestations of joint disease in the athleic horse. In: McIIwraith CW, Trotter GW, eds. Joint Disease in the Horse. 1. ed. Philadelphia: WB Saunders; 1996. p. 87-104.

Radcliffe CH, Flaminio JBF, Fortier LA. Temporal analysis of equine bone marrow aspirate during establishment of putative mesenchymal progenitor cell populations. Stem Cells Dev. 2010;19(2):269282.

Raffa RB. Mechanism of action of analgesics used to treat osteoarthritis pain. Rheum Dis Clin North Am. 2003;29(2):733-745.

Richardson DW, Dodge GR. Dose-dependent effects of corticosteroids on the expression of matrix-related genes in normal and cytokine-treated articular chondrocytes. Inflamm Res. 2003;52(1):39-49.

Riggs CM, Whitehouse GH, Boyde A. Pathology of the distal condyles of the third metacarpal and third metatarsal bones of the horse. Equine vet $J$. 1999;31(2):140-148.

Robion FC, Doizk B, Bourk L, Marcoux M, Ionescu M, Reiner A. Use of synovial fluid markers of cartilage synthesis and turnover to study effects of repeated intra-articular administration of methylprednisolone acetate on articular cartilage in vivo. J Orthop Res. 2001;19(2):250-258.

Rosis RG, Massabki OS, Kairalla M. Osteoartrite: avaliação clínica e epidemiológica de pacientes idosos em instituição de longa permanência. Rev Bras Clin Med. 2010;8(2):101-108.

Rossdale PD, Hopes R, Digby NJ, Offord K. Epidemiological study of wastage among racehorses 1982 and 1983. Vet Rec. 1985;116(3):66-69.

Rutgers M, Saris D, Yang KG, Dhert WJA, Creemers LB. Joint injury and osteoarthritis: soluble mediators in the course and treatment of cartilage pathology. Immunotherapy. 2009;1(3):435-445.

Scharstuhl A, Glansbeek HL, van Beuningen HM, Vitters EL, van der Kraan PM, van den Berg WB. Inhibition of endogenous TGF-beta during experimental osteoarthritis prevents osteophyte formation and impairs cartilage repair. J Immunol. 2002;169(1):507-514.

Schaefer CF, Stewart AA, Durgam SS, Byron CR, Stewart MC. Effects of sodium hyaluronate and triamcinolone acetonide on glyconsaminoglucan metabolism in equine articular chondrocytes treated with interleukin-1. Am J Vet Res. 2009;70(12):1494-1501. 
Schmidt TA, Gastelum NS, Nguyen QT, Schumacher BL, Sah RL. Boundary lubrication of articular cartilage - Role of synovial fluid constituents. Arthritis Rheum. 2007;56(3):882-891.

Stewart MC, Stewart AA. Mesenchymal stem cells: characteristics, sources, and mechanisms of action. Vet Clin North Am Equine Pract. 2011;27(2):243261.

Svensson CI. Interleukin-6: a local pain trigger? Arthritis Res Ther. 2010;12(5):145.

United States Department of Agriculture. Lameness and laminitis in U.S. Horses. National Animal Health Monitoring System, 2000. Acessado em: 24/06/13. Disponpivel em: <http://www.aphis.usda.gov/animal_health/nahms /equine/downloads/equine98/Equine98_dr_Lamen ess.pdf>

van Weeren PR, Brahma PA. Physiology and pathology of the equine joint. Pferdeheilkunde. 2001;17(4):307-318.

van Weeren PR, de Grauw JC. Pain in osteoarthritis. Vet Clin Equine. 2010;26(1):619-642.

van Weeren PR, Firth EC. Future tools for early diagnosis and monitoring of musculoskeletal injury: biomarkers and CT. Vet Clin North Am Equine Pract. 2008;24(1):153-175.
Veiga, A.C.R. Estudo retrospectivo de casuística, abrangendo metodologia diagnóstica da osteoartrite em equinos. Dissertation. Programa de PósGraduação em Clínica Veterinária da Faculdade de Medicina Veterinária e Zootecnia da Universidade de São Paulo, São Paulo, 2006. 79 p.

Walshe TE, Saint-Geniez M, Maharaj AS, Sekiyama E, Maldonado AE, D'Amore PA. TGF- $\beta$ is required for vascular barrier function, endothelial survival and homeostasis of the adult microvasculature. PLoS ONE. 2009;4(4):e5149.

Wang EA, Rosen V, D'Alessandro JS, Bauduy M, Cordes P, Harada T. Recombinant human bone morphogenetic protein induces bone formation. Proc Natl Acad Sci. 1990;87(6):2220-2224.

Wozney JM. The bone morphogenetic protein family and osteogenesis. Mol Reprod Dev. 1992;32(2):160167.

Yang X, Chen L, Xu X, Li C, Huang C, Deng CX. TGF-beta/Smad3 signals repress chondrocyte hypertrophic differentiation and are required for maintaining articular cartilage. Cell Biol. 2001;153(1):35-46.

Received: January 15, 2016; Accepted: April 25, 2016 